Int. J. Electrochem. Sci., 14 (2019) 10227 - 10247

\title{
Ketamine Drug as an Inhibitor for the Corrosion of 316 Stainless Steel in 2M HCI Solution
}

\author{
M.Abdallah ${ }^{1,2, *}$, M. Alfakeer ${ }^{3}$, Amal M. Alonazi $^{3}$, Salih S. Al-Juaid ${ }^{4}$ \\ ${ }^{1}$ Chemistry Department, Faculty of Applied Science, Umm Al-Qura University, Makkah, Saudi \\ Arabia \\ ${ }^{2}$ Chemistry Department, Faculty of Science, Benha University, Benha, Egypt \\ ${ }^{3}$ Chemistry Department, Faculty of Science, Princess Nourah bint Abdulrahman University, Riyadh, \\ Saudi Arabia \\ ${ }^{4}$ Chem. Dept., Faculty of Science, King Abdulaziz University, Jeddah, Saudi Arabia \\ *E-mail: metwally555@yahoo.com
}

doi: $10.20964 / 2019.11 .10$

Received: 15 June 2019 / Accepted: 15 August 2019 / Published: 7 October 2019

\begin{abstract}
Ketamine drug was examined as an inhibitor of the corrosion of 316 stainless steel in $2 \mathrm{MHCl}$ solution using weight loss, galvanostatic polarization, potentiodynamic anodic polarization and electrochemical impedance spectroscopy measurements. The inhibitory efficiency was increased with increased concentration of ketamine and reduced at high temperature. The ketamine acted as mixed inhibitor. The inhibitory mechanism was interpreted by the formation of chelating compound strongly adsorbed onto the 316SS surface. The adsorption conformed Langmuir isotherm. Ketamine drug inhibits the pitting corrosion of $316 \mathrm{SS}$ by converting the pitting potential in the positive direction. The activation and adsorption of thermodynamic parameters were computed and clarified. A quantum calculation and its relationship to the inhibition efficiency of the ketamine drug was carried out using the density functional theory (DFT) by Hartree Fock (HF) level and Becke three-parameter DFT/B3LYP [26], together with Valence Triple Zeta plus Polarization and Diffuse 6-311++G (d, p).
\end{abstract}

Keywords: Ketamine drug, corrosion inhibitors, polarization, adsorption, DFT

\section{FULL TEXT}

(C) 2019 The Authors. Published by ESG (www.electrochemsci.org). This article is an open access article distributed under the terms and conditions of the Creative Commons Attribution license (http://creativecommons.org/licenses/by/4.0/). 